\title{
A systematized literature review of student learning, participation, and engagement experience in engineering massive open online courses (MOOCs)
}

\section{Mrs. Huma Shoaib, Purdue University}

Huma Shoaib is a graduate student working jointly between Engineering Education and Weldon School of Biomedical Engineering at Purdue University. Her research focus is computational thinking and understanding computational as well as engineering identity development in undergraduate students to overcome issues related to women persistence in undergraduate engineering programs. 


\title{
A systematized literature review of student learning, participation, and engagement in engineering massive open online courses.
}

\begin{abstract}
This report is a systematized literature review on articles relevant to student learning, participation, and engagement in engineering massive open online courses. Learning about student participation and engagement in MOOCs will help with increasing student retention in MOOCs. The review details the systematized search of relevant databases for journal publications related to student learning, participation, and engagement in engineering massive open online courses. 21 peer-reviewed journal articles were retrieved and shortlisted from three databases: Education Source, ERIC, and Scopus. The focus of these articles was massive open online course participants (students) and what are their experiences in terms of learning, participation, and engagement. Four emergent themes were found in the surveyed literature. The first theme was the identification of different learning groups in MOOC participants. The second theme was the identification of participation patterns in MOOC participants. The third theme identified a correlation between student engagement and other factors like student retention and grades in MOOCs. Finally, the fourth theme was the identification of a gap for improvement in engineering massive open online courses.
\end{abstract}

\section{Introduction and Literature Review}

Massive open online course (MOOC) is defined by Siemens (2010) as a web-based course available for free enrollment by any participant regardless of their physical location. Fischer (2014) gave a similar definition of massive online courses as short-term courses designed for higher education with massive enrollments and a promise to provide free education for all. He complemented Siemens (2010) definition by adding that these courses are offered in different areas of interests.

Massive open online courses are a game changer in the history of engineering education. These courses are free of cost (open), without the hassle of coming to a physical location (online) and are of high quality. Hence, these courses appeal to learners who cannot afford to pay heavy college fees and learners who have the difficulty of commuting to a physical classroom in order to access the information being taught Kay (2013).

Despite the potential and hype associated with MOOCs, they have challenges as well. Retention rates overall are typically very low. Armellini (2016) reported that only $10 \%$ participants complete the them. There is a need to understand the reasons behind the low retention and persistence rate of students in these courses. One way to understand the reason of low persistence in MOOCs is to explore the literature about student learning, engagement, and participation in them in order to get an essence of their impact. Knowing about the big picture will help with student persistence in MOOCs. 
The systematize review will identify student learning categories and styles because of a number of reasons.

Firstly, since they are free of cost, massive open online courses have large enrollments. London (2016) reports that student learning success has been a major question of concern since the emergence of massive open online courses. Monitoring student learning in large classrooms is a challenge. It's a challenge because as the number of students increase it is difficult to keep track of learning styles and success of all students.

Secondly, in traditional classrooms, there is a student-teacher interaction which helps the teacher identify the students' learning style. When the teacher is not available to assess the student in the technological MOOC environment it becomes a challenge to assess the learning style because the student and instructor are not at the same physical setting rather are virtually connected through a platform.

In addition to student learning, it is also important to know about how students engage and participate in MOOCs. Because it is reported by Barba (2016) that the strongest predictor of student performance is participation, followed by motivation. Research literature can help to address how students participate in MOOCs and how this participation can be improved. Why and how people come to MOOCs needs to be better understood and importantly what factors contribute to learners' MOOC performance. Addressing these questions is important, as motivation is reported to be the second biggest factor to help increase student persistence in MOOCs Barba (2016).

There is a need to exhaust and synthesize previous literature in a systematic manner to know about student learning styles, measured of student learning success and patterns of participation and engagement in MOOCs. Synthesizing relevant information through systematized literature review will help give an insight into how student experience can be improved in terms of learning, engagement, and participation so that students persist in MOOCs.

\section{Scope}

This literature review focuses on student learning, participation, and engagement in engineering massive open online courses. Massive open online courses get large enrollments because of being open (free of cost). Because of open enrollment and no restriction on age to get enrolled in massive open online courses, it is very difficult to limit the scope of this systematized review to high school, undergraduate or graduate students. Neither, the literature can be narrowed down to a specific geographic region because massive open online courses surpass the need of being physically available in a classroom. 


\section{Research Question}

Although this literature review study fits inside a larger subspace of engineering learning systems (technological innovation in teaching and learning pedagogy) it will help create a better understanding of massive open online courses in engineering. This systematic literature review will identify what the literature says about student learning, participation, and engagement in engineering massive open online courses?

\section{Methods}

In accordance with the systematized literature review process Booth (2016), a set of selected databases were queried using a nearly identical search string in order to capture articles that would plausibly address the research question. Three databases were selected for this project: Education Source, ERIC, and Scopus. Education Source and ERIC are databases that contain sources related to education. These databases were selected to align with the goal of the project to look into literature which is focused on engineering massive open online courses and their role in student learning, participation, and engagement. The final database, Scopus, is the largest source of peer-reviewed literature. Such a broad reach is important to address the overarching research goal because of the field-spanning nature of massive online courses in engineering. A three-part search string was adapted to query each database, as displayed in Table 2.

The first part of the search string extracted documents that had a title, keywords or abstract (depending on the database) that included "moocs" or "massive open online courses". A broader search of full text was conducted for "engineer*". The final part of the search string consulted the full text for "student engagement OR student learning OR student participation".

The inclusion of articles that discuss student engagement, learning, and participation in engineering massive open online courses were acquired. Either within the search string (Scopus) or through a refining menu (all others), steps were taken to include only journal articles within the reported results. The focus of the systematized review was to find peer-reviewed journal articles which were focused on student learning, participation and engagement experience in engineering massive open online courses.

The applied search strings and subsequent results from each database are shown in Table 1. There were 11 results in Education Source, 23 in Scopus, and one result in ERIC. Following the method advised in Preferred Reporting Items for Systematic reviews and Meta-Analyses (PRISMA) guide Moher (2009), four duplicates were removed from the collated databases for a total of journal articles 35. The PRISMA flowchart Moher (2009) for the searching and refining process can be seen in Figure 1 at the end of this section. 
The review was limited to engineering MOOCs. Popular international massive open online platforms were selected from countries whose first language is English. The review was also limited to students who either completed or were enrolled in engineering MOOCs regardless if they completed the course or not because the review focuses on the student learning experience. The only peer-reviewed journal articles written in the English language were considered. Peer-reviewed journal articles were selected from 2010 onwards because MOOCs emerged in 2011. The limitations for refining the corpus of acquired peer-reviewed journal articles can be seen in Table 2.

Table 1. Complete search strings and results of the database query

\begin{tabular}{|l|l|l|}
\hline Search String & Database & Retrieved Articles \\
\hline $\begin{array}{l}\text { TI ( "moocs" or "massive open online } \\
\text { courses") OR KW ( "moocs" or "massive } \\
\text { open online courses") OR AB( "moocs" or } \\
\text { "massive open online courses") AND } \\
\text { engineer* AND student engagement OR } \\
\text { student learning OR student participation }\end{array}$ & Education Source & 11 \\
\hline $\begin{array}{l}\text { TI ( "moocs" or "massive open online } \\
\text { courses") OR KW ( "moocs" or "massive } \\
\text { open online courses") OR AB( "moocs" or } \\
\text { "massive open online courses") AND } \\
\text { engineer* AND student engagement OR } \\
\text { student learning OR student participation }\end{array}$ & $\begin{array}{l}\text { Eric (EBSCO } \\
\text { ( TITLE-ABS-KEY ( }\end{array}$ & 1 \\
$\begin{array}{l}\text { "moocs" OR "Massive Open Online } \\
\text { Courses" ) AND ALL ( engineer* } \\
\begin{array}{l}\text { AND ALL ( student AND } \\
\text { engagement OR student AND } \\
\text { learning OR student AND participation ) } \\
\text { AND DOCTYPE ( ar ) AND ( } \\
\text { LIMIT-TO ( DOCTYPE , "ar" ) ) }\end{array}\end{array}$ & & \\
\hline $\begin{array}{l}\text { Total Number of Articles After Duplication Removal } \\
\text { Acopus }\end{array}$ & & \\
\hline
\end{tabular}

Table 2. Inclusion criteria

\section{Limitations Criteria}

- Massive online courses with large student enrollment

- Peer Reviewed Journal Articles

- Written in English Language 
- Focus on Engineering from (STEM)

- $\quad$ Age of Article (2010 - 2019)

- Focus on student learning, engagement, and participation

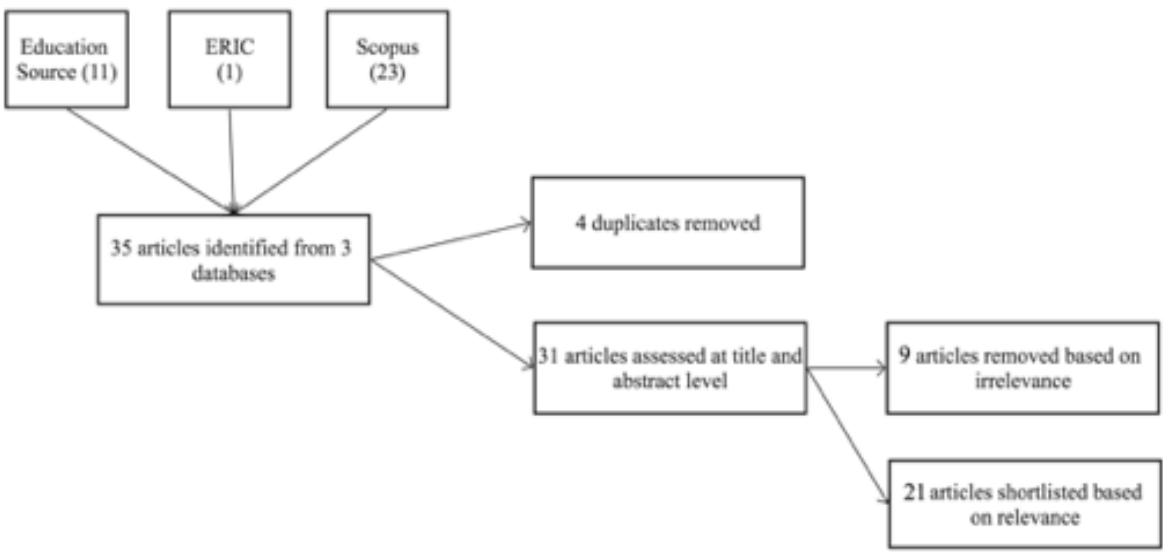

Figure 1. Adaptation of the PRISMA flowchart for described search process Moher (2009)

\section{Findings}

The findings are constructed on the basis of the research question. The focus is on student learning, participation, and engagement. Hence, the research studies were read to answers questions pertaining to these factors. I categorized my literature review into three sections: Student learning in MOOCs, Student Participation in MOOCs and Student Engagement in MOOCs.

\section{Student Learning in MOOCs}

The first emergent theme found while serving the literature about student learning in MOOCs was student characteristics. Student learning in surveyed literature is expressed in terms of student learning behavior experience. MOOC learners are classified into different groups based on learning behavior. This classification is performed in order to segregate students on the basis of their learning behaviors and capabilities.

Zhong (2017) investigated the learning behavior and learning processes in MOOC students. Students were classified on basis of their learning behaviors of being active or 
passive learners. Tseng (2016) Classify MOOC learners into three categories; active learner, passive learner, and bystander. Active learners are those students who perform well in terms of timely submission of assignments or homework, pay attention to video content, complete the course and attain better grades as compared to other MOOC learners. Passive learners have opposing characteristics to active learners: they have limited participation. Whereas, bystander does not participate in the learning process.

Koller (2013) grouped MOOC learners into two main categories "browsers" and "committed learners." Active, passive and community contributors are placed under the "committed learners" category. Here active learners show characteristics of completing assignments and homework. Passive learners had characteristics of viewing course content, but they expressed limited participation on course forum and assignment completion. Community contributors also actively participated in course, but their interest was more inclined towards forum discussions.

Chang (2015) focused on student learning styles. They found out that students who were less interested in using technology were afraid of learning in technology environments and were at risk of discontinuing their involvement in the course. They named these students low reflective learners and suggested to engage these students in group activities to enhance their participation in the course.

The second emergent theme was factors which affect student learning process. It was found from the literature that several factors affect student learning in MOOCs. Selfmotivation and time management were factors identified in Kay (2013). These factors affected performance and completion rate in MOOC participants. (Armellini, 2016; Buhl, 2018; Feng 2017) reported pedagogical innovation as an important factor in student learning success. Student participation has a positive correlation with student learning outcome Liang (2014). In the same manner Lu (2017) reported that student engagement has a positive impact on student learning. Video resources including teacher are reported by Feng (2017) to be the main way to learn in MOOCs.

Thirdly, information on how student learning success is assessed in MOOCs was found as an emergent theme. The parameter for student learning is reported to be grading and analytics. Kay (2013) report that Quantitative data is provided to the student in form of raw scores or percentages on completion of modules or full course as grading. The average scores of assignments and quizzes are reported to reflect the learning outcomes of participating students Liang (2014). Also, Armellini (2016) report course completion rate as a student learning success measure.

\section{Student Participation in MOOCs}

Student participation in MOOCs is an essential factor to assess the quality of a MOOC. Increasing student participation will help in student persistence. Santos (2014) reported after analyzing student behavior in MOOCs that the students which show more participation in course activities have better chances of passing the course. Also, 
according to Phan (2015) student participation and student course performance are directly related to reach other.

The first identified finding in student participation was identification of participation patterns in MOOCs. Eynon (2014) looked into student interaction and engagement patterns in MOOCs they analyzed that the participants assembled and dispersed as crowds instead on showing characteristics or forming a learning community, they also report that the students who show participation in course forums are high performers than those who don't show much participation. Phan (2015) also provided student participation pattern in MOOCs. Participation is reported to be trying an assignment, submitting an assignment, and active usage of discussion forum.

The second finding was identification of factors which are related to student participation in MOOCs. Williams (2018) reported that age was positively associated with MOOCs participation. Eynon (2014) reported that young adults from western world tend to show greater participation in MOOC forums. Evans (2016) reported that students who register earlier than the course start date show better persistence as compared to students who register late.

Yang (2017) reported that a course quality is a key factor for student participation. Quality is divided into five constructs: system quality, course quality, service quality, perceived ease of use, and perceived usefulness. Perceived usefulness and perceived ease of use mediated relationship between system quality, course quality, service quality, and the continuance intention of MOOC users. They suggested course information should be clear and understandable as quality affects participation. Liang (2014) also reported "perceived ease of use" as determinant of student participation in MOOCs. usefulness and ease of use of MOOC affect MOOC participation. Sadhasivam (2014) report prior knowledge of technology usage as an important factor towards MOOC participation.

The third finding presented suggestions to improve and assess student participation in MOOCs. Evans (2016) suggested that valuable and vital content information should be added in the first video lecture of each week as students tend to watch those videos more as compared to others. They also suggest adding a pre course survey for the student before start of the course as the students who filled the pre course survey in STEM courses demonstrated better participation and persistence rate as compared to the ones who did not. Williams (2018) suggested that a better model to assess MOOCc participation success would be to understand the reasons for taking the course by participating students. The study found that students' intentions and their level of intrinsic motivation were positively related to the participation in STEM courses.

\section{Student Engagement in MOOCs}

Student engagement plays a vital role in towards persistence in MOOCs. Anderson (2014) reported that learning about student interaction with MOOCs is very important, as it will provide insight into designing better MOOCs and check their effectiveness in 
teaching and learning. The literature on student engagement and participation in MOOCs has no clear boundaries. However, studies have identified and associated student characteristics with engagement in the same way they were found to be associated with student learning. Some studies have also reported on how students engage in MOOCs and how engagement can be improved for designing better MOOCs.

Studies have provided information on different ways and patterns of student engagement in MOOCs. Tseng (2016) proposed the importance of discussion forum feature in MOOCs; its presence is essential for assessment and engagement of student learning performance. They reported that the presence of a discussion forum in MOOCs is correlated with student retention. The ease of use of and responsiveness of discussion forum is also reported to increase student engagement in MOOCs by Phan (2015).

Kizilcec (2013) classified student engagement patterns on a famous MOOC platform called Coursera. The authors classified students in four categories of learner engagement. "On track" these students submit assignments on time. "Behind" submit assignments but after submission deadline. "Auditing" who just browse the course content and don't submit assignments. Lastly, "Out" students don't participate in the course in any manner after enrollment.

Early engagement in course is predictive of achievement according to Li (2018). They reported that the group students who engaged in watching lecture videos, taking quizzes and participating in discussion forums showed an overall better performance in the MOOC. In some studies; (Xiong, 2018; Alcarria, 2018) peer assessment is reported as a form of student engagement in MOOCs. However, peer assessment is not related with performance or achievement rather with student characteristics and behavior as well as social engagement. Williams (2018) reported having learner goals in STEM related MOOCs effected student engagement. These goals can be related to interest or use of information in future career. They also report that engagement is measured in terms of certification or activity completion.

Anderson (2014) investigated that the students' engagement in the MOOC is correlated with the students' final grade in the courses. Phan (2015) learners who demonstrated active engagement tended to out perform the ones who did not prioritize the similar trait. Active engagement is also shown to be one of the strong traits of a high quality MOOC. Lu (2017) reports that knowing about student engagement level can help identify at risk students in a timely manner.

Table 3. Classification of literature according content related to student learning, participation, and engagement.

\begin{tabular}{|l|l|l|l|}
\hline Author (Year) & Student Learning & Student Participation & Student Engagement \\
\hline Alcarria (2018) & & & $\checkmark$ \\
\hline Anderson (2014) & $\checkmark$ & & $\checkmark$ \\
\hline Armelini (2016) & $\checkmark$ & & \\
\hline
\end{tabular}




\begin{tabular}{|l|l|l|l|}
\hline Buhl (2018) & $\checkmark$ & & \\
\hline Chang (2015) & $\checkmark$ & $\checkmark$ & \\
\hline Evans (2016) & & $\checkmark$ & \\
\hline Eynon (2014) & & & \\
\hline Feng (2017) & $\checkmark$ & & \\
\hline Kay (2013) & $\checkmark$ & & $\checkmark$ \\
\hline Kizilcec (2013) & & & \\
\hline Koller (2013) & $\checkmark$ & $\checkmark$ & $\checkmark$ \\
\hline Li (2018) & & & \\
\hline Liang (2014) & $\checkmark$ & $\checkmark$ & $\checkmark$ \\
\hline Lu (2017) & $\checkmark$ & $\checkmark$ & $\checkmark$ \\
\hline Phan (2014) & & $\checkmark$ & \\
\hline Sadhasivam (2014) & & & \\
\hline Santos (2014) & & $\checkmark$ & \\
\hline Tseng (2016) & $\checkmark$ & & \\
\hline Williams (2018) & & & \\
\hline Xiong (2018) & & $\checkmark$ & \\
\hline Zhong (2017) & & & \\
\hline
\end{tabular}

\section{Discussion}

The emergent findings in student learning were; categorization of learners according to their learning style, factors which are related to student learning, and student learning assessment parameters. It was found that "perceived ease of use" counts in student learning as well as participation. The perceived ease of use of MOOC is directly correlated with student learning and participation.

In literature there were no proper boundaries found to be established, in order to differentiate between student engagement and participation. Usage of feedback and discussion forums is reported to be participation as well as engagement. However, engagement and participation patterns were identified from literature which mainly constitute attempt and submission of assignment, active engagement in discussion forums and peer assessment. The literature further provided suggestions on increasing student participation and engagement as both of these factors were found to be directly related with student learning and persistence in the course.

Four finding emerged found from the surveyed literature. The first finding is the identification of different learning groups in MOOC participants. The second finding is 
the identification of participation patterns in MOOC participants. The third finding has identified a correlation between student engagement and other factors like student retention and grades in MOOCs. Finally, the fourth finding was the identification of gap for improvement in engineering massive open online courses. The potential implication of this study is student retainment and persistence in MOOCs and its impact on the future design process of massive open online courses in engineering.

\section{References}

Alcarria, R., Bordel, B., de Andrés, D. M., \& Robles, T. (2018). Enhanced peer assessment in MOOC evaluation through assignment and review analysis. International Journal of Emerging Technologies in Learning, 13(1), 206-219. https://doi.org/10.3991/ijet.v13i01.7461

Anderson, A., Huttenlocher, D., Kleinberg, J., \& Leskovec, J. (2014). Engaging with massive online courses. International conference on world wide web. 23(14). 687-698.

Armellini, A., Rodriguez, P., \& Cecilia, B. (2016). Are Massive Open Online Courses (Moods) pedagogically innovative?. Journal of Interactive Online Learning. 14(1). 17-28.

Barba, P.G., Kennedy, G.E., \& Ainley, M.D. (2016). The role of students' motivation and participation in predicting performance on a MOOC. Journal of Computer Assisted Learning. 32. 218-231. doi:10.1111/jcal.12130.

Booth, W. C., Colomb, G. G., Williams, J. M., Bizup, J., \& Fitzgerald, T. W. (2016). The craft of research. Chicago: University of Chicago Press.

Brahimi, T., \& Sarirete, A. (2015). Learning outside the classroom through MOOCs. Computers in Human Behavior, 51, 604-609. https://doi.org/10.1016/j.chb.2015.03.013

Chang, R. I., \& Chun Fu Lin2,. (2015). Survey of learning experiences and influence of learning style preferences on user intentions regarding MOOCs. British Journal of Educational Technology, 46(3), 528-541. https://doi.org/10.1111/bjet.12275

Evans, B. J., Baker, R. B., \& Dee, T. S. (2016). Persistence patterns in massive open online courses (MOOCs). Journal of Higher Education, 87(2), 206-242. https://doi.org/10.1353/jhe.2016.0006

Eynon, R., \& Gillani, N. (2014). Communication patterns in massively open online courses. The Internet and Higher Education. 23. 18-26. doi:https://doi.org/10.1016/j.iheduc.2014.05.004. 
Feng, L., Jiang, H., Wang, J., 446485189@qq.com, \& Gong, Y. (2018). Design, implementation and evaluation of MOOCs and DBL-based cross-registration. Computer Applications in Engineering Education, 26(2), 405-412. https://doi.org/10.1002/cae.21893

Fischer, G., (2014). Beyond hype and underestimation: identifying research challenges for the future of MOOCs. Distance Education. 35. 149-158. doi:10.1080/01587919.2014.920752.

Gillani, N. (2014). Communication patterns in massively open online courses. Internet and Higher Education, 23, 18-26. https://doi.org/10.1016/j.iheduc.2014.05.004

Judy, K., Peter, R., Elliot, D., \& Bob, K. (2013). MOOCs: So many learners, so much potential .... Intelligent Systems, IEEE. 28. 70-77. doi:10.1109/MIS.2013.66.

Kizilcec, R. F., Piech, C., \& Schneider, E. (2013). Deconstructing disengagement: Analyzing learner subpopulations in massive open online courses. Proceedings of the Third International Conference on Learning Analytics and Knowledge. 170179. doi: $10.1145 / 2460296.2460330$.

Koller, K., Ng, A., Do, C., \& Chen, Z. (2013). Retention and intention in massive open online courses. Educause Review. 28(3). 62-63.

Liang, D., Jia, J., Wu, X., Miao, J., \& Wang, A. (2014). Analysis of learners' behaviors and learning outcomes in a massive open online course. Knowledge Management and E-Learning, 6(3), 281-298.

London, J., \& Young, C. (2016). The role of Massive Open Online Courses (MOOCs) in engineering education: Faculty perspectives on its potential and suggested research directions. 32 . 1788-1800.

Lu, O. H. T. ., Huang, J. C. H. ., Huang, A. Y. Q. ., \& Yang, S. J. H. . (2017). Applying learning analytics for improving students engagement and learning outcomes in an MOOCs enabled collaborative programming course. Interactive Learning Environments, 25(2), 220-234.

Moher, D., Liberati, A., Tetzlaff, J., Altman, D. G., Altman, D., Antes, G., \& Tugwell, P. (2009). Preferred reporting items for systematic reviews and meta-analyses: The PRISMA statement (Chinese edition). Journal of Chinese Integrative Medicine, 7(9), 889-896. http://doi.org/10.3736/jcim20090918

Sadhasivam, J. (2014). Educational paradigm shift: Are we ready to adopt MOOC? International Journal of Emerging Technologies in Learning, 9(4), 50-55. https://doi.org/10.3991/ijet.v9i4.3756. 
Santos, J. L., Klerkx, J., Duval, E., Gago, D., \& Rodríguez, L. (2014). Success, activity and drop-outs in MOOCs: an exploratory study on the UNED COMA courses. Learning Analytics and Knowledge. 4. 98-102. doi:10.1145/2567574.2567627.

Tseng, S., Task, Y., Yu, L., Chan C., \& Lai, K. R. (2016). Who will pass? Analyzing learner behaviors in MOOCs .Research and Practice in Technology Enhanced Learning. 11(1). 1-11. doi:10.1186/s41039-016-0033-5.

Wang, L., Hu, G., \& Zhou, T. (2018). Semantic analysis of learners' emotional tendencies on online MOOC education. Sustainability (Switzerland), 10(6). https://doi.org/10.3390/su10061921

Williams, K. M. ., R. E. ., rose. Corliss, S. B. ., Stephanie., \& Reilly, E. D. (2018). Examining student characteristics, goals, and engagement in Massive Open Online Courses. Computers \& Education, 126, 433-442. https://doi.org/10.1016/j.compedu.2018.08.014

Xiong, Y., \& Suen, H. K. (2018). Assessment approaches in massive open online courses: Possibilities, challenges and future directions. International Review of Education, 64(2), 241-263. https://doi.org/10.1007/s11159-018-9710-5.

Yang, M., Shao, Z., Liu, Q., \& Liu, C. (2017). Understanding the quality factors that influence the continuance intention of students toward participation in MOOCs. Educational Technology Research and Development, 65(5), 1195-1214. https://doi.org/10.1007/s11423-017-9513-6

Zhong, S., Li, Y., Liu, Y., \& Wang, Z. (2017). A computational investigation of learning behaviors in MOOCs. Computer Applications in Engineering Education. 25(5). 693-705. doi:10.1002/cae.21830.

Siemens, G., \& Cormier, D. (2010). Through the Open Door: Open Courses as Research, Learning, and Engagement. EDUCAUSE. 45. 30-39. 